\title{
Acute Appendicitis - Propedeutics and Diagnosis
}

\author{
Andy Petroianu \\ Department of Surgery, Medical School of the Federal University of Minas Gerais, \\ Brazil
}

\section{Introduction}

Appendicitis is the most common abdominal emergency. The lifetime risk of developing appendicitis is approximately $7 \%$ and it is the most common acute abdominal emergency that requires surgical treatment. The overall incidence of this condition is approximately 11 cases per 10,000 population per year. Acute appendicitis may occur at any age, although it is relatively rare at the extremes of age. There is an increased incidence in patients between the ages of 15 and 30 years during which time the incidence increases to 23 per 10,000 population per year; thereafter, the disease incidence declines with age. $[1,2,3,4,5,6]$

A male preponderance exists, with a male to female ratio of 1.1 to $3: 1$; the overall lifetime risk is $9 \%$ for males and $6 \%$ for females. A difference in diagnostic error rate ranges from $12 \%$ to $23 \%$ for men and $24 \%$ to $42 \%$ for women. Most of patients are of white skin colours $(74 \%)$ and is very rare in black skin colour $(5 \%)$. [1,2,3,7]

While the clinical diagnosis may be straightforward in patients who present with classic signs and symptoms, atypical presentations may result in diagnostic confusion and delay in treatment. [8]

\section{Historical aspects}

Appendicitis was rare in the past. There appears to be no record of early physicians, from Hippocrates to Moses Maimonides. The first anatomic drawings of the appendix date back to circa 1492 when Leonardo Da Vinci described an earlike structure he termed the orecchio arising from the caecum. Berengario Da Carpi, a physician-anatomist, made his description of the appendix in 1521. In 1543, Andreas Vesalius published the first detailed illustration of an appendix. [1]

After the studies of Morgagni, published in 1719, little additional information regarding the gross anatomy of the appendix was added. Although the anatomy of the appendix was clearly defined by these early anatomists, its pathology and treatment remained controversial for the next 300 years. [9]

Jean Fernel, the French court physician to Catherine de Medici, has been credited with the first description of acute typhlitis (derived from the Greek typhlon for caecum) in 1554 that occurred in a 7-year-old girl who died of a perforated appendix. At autopsy, Fernel noted luminal obstruction of the caecum and appendix with necrosis, perforation, and spillage of contents into the abdominal cavity. Other physicians, surgeons and anatomists described 
diseases on this organ. Even the great physiologist John Hunter described a gangrenous appendix, encountered at an autopsy that he performed on Colonel Dalrymple in 1767. $[1,5,9]$

In 1711, Lorenzo Heister, a professor of surgery at Helmstedt, was the first to suggest the appendix as the likely site of primary inflammation and abscess formation in acute typhlitis. Claudius Amyand, Sergeant Surgeon to George II, performed the first known appendectomy in 1735. Early reports of perityphlitis and typhlitis in the 19th century appeared to describe a new clinical phenomenon. In 1839, Bright and Addison, the great physicians of Guy's Hospital, clearly described the symptoms of appendicitis and stated that the appendix was the cause of many inflammatory processes of the right iliac fossa. $[5,9]$

It has been 125 years since Reginald Heber Fitz first described the relationship between appendicitis with perforation, presenting as a right lower quadrant abscess. Fitz was the Shattuck Professor of Pathological Anatomy at Harvard University. On June 18, 1886, he presented a paper to the Association of American Physicians in Washington, D.C., entitled "Perforating inflammation of the vermiform appendix with special reference to its early diagnosis and treatment". He went on to describe the clinical features of appendicitis and proposed early surgical removal of the appendix. His remarks led to the increasing recognition of appendicitis as an important clinical entity and appendectomy as its appropriate treatment. Willard Parker of New York, published a paper in 1867 recounting his experiences, beginning in 1843 , with drainage of appendiceal abscesses. $[9,10,11]$

The first known surgical removal of the appendix occurred in 1735. Claudius Amyand, a founder of St. George's Hospital in London, operated on an 11-year-old boy with a longstanding scrotal hernia and a faecal fistula of the thigh. Through a scrotal incision, the hernia was opened, revealing omentum surrounding an appendix that was perforated by a pin, giving rise to the faecal fistula. The appendix and omentum were amputated, and the fistula opened with recovery. [9]

In 1880, Lawson Tait operated on a 17-year-old girl, removing a gangrenous appendix. Abraham Groves of Fergus, from Ontario. removed an inflamed appendix from a 12-yearold boy with pain and tenderness in the right lower quadrant of the abdomen in 1883. In 1884, Mikulicz performed an appendectomy, but the patient did not survive. In 1885, Kronlein of Zurich successfully performed an appendectomy. Also in 1885, CharterSymonds of London performed such an operation. Thomas G. Morton of Philadelphia, in 1887, reported a successful appendectomy with drainage of an abscess in a 27 -year-old patient. With the advocacy of early surgical intervention, the mortality rate of acute appendicitis over the 15 years succeeding Fitz's manuscript dropped from 50\% to $15 \%$. $[1,9,12]$

In a presentation to the New York Surgical Society in 1889, Charles McBurney described his experience with many successful operations for early removal of the appendix. He also described his, now famous, McBurney's point. Their surgical aim was to operate in a timely fashion before appendiceal perforation and peritonitis developed. The early clinical diagnosis and operative intervention recommended by McBurney over a century ago remains the standard of care for the practicing emergency physician today. The lateral muscle-splitting or "gridiron" incision is generally called the McBurney incision, however it was used firstly by Lewis McArthur of Chicago, and was described in 1894. J. W. Elliot advocated a transverse skin incision in 1896 . $[1,5,8,9,10]$ 
Nothing new happened for almost 90 years until Semm, a German gynaecologist, removed an appendix, in 1980, by a laparoscopic approach. During almost one decade he was disbelief in the surgical community, but today this is considered the best surgical approach to the appendix. $[10,13,14]$

The idea that appendicitis may resolve spontaneously is not new. In 1908 Alfred Stengel wrote: "Treated in a purely medical or tentative manner, the great majority of patients with appendicitis recover". The first successful instances of the nonoperative medical treatment of appendicitis occurred on board US Navy submarines during combat patrol in World War II. The practice of nonoperative medical treatment of appendicitis continued successfully on board US Navy submarines after the end of this war. The first report on the non-operative management of appendicitis was published by Coldrey in 1959. Thirteen additional cases of appendicitis were treated medically from 1960 to 1964 on board US Navy Polaris submarines. There were two failures $(15.4 \%)$ resulting from gangrenous appendicitis (one medically evacuated and one appendectomy performed on board with great difficulty). $[15,16,17]$

\section{Anatomy}

Embryologically, the appendix is part of the caecum from which it originates where the three taeniae coli coalesce at the distal aspect of the caecum. In addition, the appendix contains an abundance of lymph follicles in the submucosa, numbering approximately 200. The highest number of lymph follicles occurs in the 10- to 20-year-old age group; they decline in number after age 30 and are totally absent after age 60. [5]

The adult appendix is a long diverticulum averaging 5 to $10 \mathrm{~cm}$ in length that arises from the posteromedial wall of the caecum, approximately $3 \mathrm{~cm}$ below the ileocaecal valve. The mean width is 0.5 to $1.0 \mathrm{~cm}$. Although the relationship of the base of the appendix to the caecum essentially is constant, the remainder of the appendix is free, which accounts for its variable location in the abdominal cavity. The orientation of the appendix in the abdomen has classically been described as lying in the right lower quadrant, at a position approximately one-third the distance from the right anterior superior iliac spine to the umbilicus. This region is also known as McBurney's point. [2]

The various positions of the appendix are conveniently categorized into the following locations: $[5,8,18]$

- paracolic - the appendix lies in the right paracolic gutter lateral to the caecum (35\%);

- retrocaecal - the appendix lies posterior to the caecum and may be partially or totally extraperitoneal (30\%);

- $\quad$ preileal - the appendix is anterior to the terminal ileum $(1,5 \%)$;

- $\quad$ postileal - the appendix is posterior to the ileum (1,5\%);

- $\quad$ promontoric - the tip of the appendix lies in the vicinity of the sacral promontory $(1 \%)$;

- $\quad$ pelvic - the tip of the appendix lies in or toward the pelvis (30\%);

- $\quad$ subcaecal - the appendix lies inferior to the caecum (1\%).

This variability in location may greatly influence the clinical presentation in patients with appendicitis. A more recent imaging-based study showed that in only $4 \%$ is the appendix located at the classic McBurney point (the junction of the lateral and middle third of the line between the anterior superior iliac spine and the umbilicus). $[5,8,18]$ 


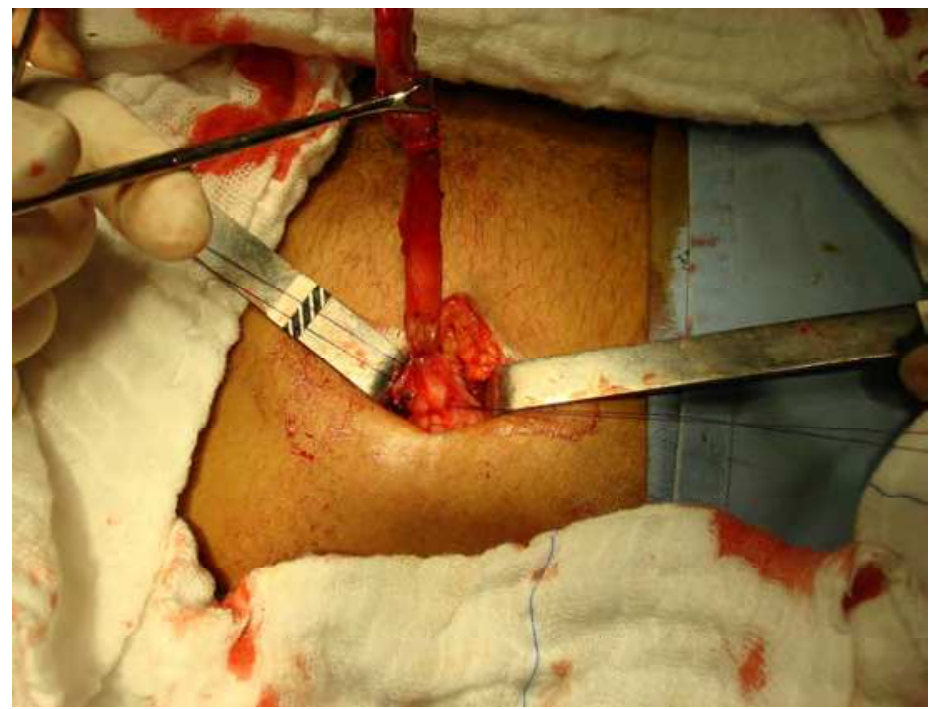

Fig. 1. An appendix being removed through an incision on the McBurney's point.

\section{Pathophysiology}

The function of the appendix is not clearly understood, although the presence of lymphatic tissue suggests a role in the immune system. In humans it is regarded as a vestigial organ, and acute inflammation of this structure is called acute appendicitis. The appendicitis may be classified into the following terminology: [1]

- simple appendicitis - inflamed appendix, in the absence of gangrene, perforation, or abscess around the appendix;

- complicated appendicitis - perforated or gangrenous appendicitis or the presence of periappendiceal abscess.

The relatively high-refined, low-fibre diet of industrialized countries has been implicated as an aetiologic factor in the development of appendicitis. The primary pathogenic event in the majority of patients with acute appendicitis is believed to be luminal obstruction. This may result from a variety of causes, which include faecaliths, lymphoid hyperplasia, foreign bodies, parasites, and both primary (carcinoid, adenocarcinoma, Kaposi sarcoma, and lymphoma) and metastatic (colon and breast) tumours. Faecal stasis and faecaliths may be the most common cause of appendiceal obstruction, followed by lymphoid hyperplasia, vegetable matter and fruit seeds, barium from previous radiographic studies and intestinal worms (especially ascarids). The prevalence of appendicitis in teenagers and young adults suggests a pathophysiologic role for lymphoid aggregates that exist in abundance in the appendix in this age group. $[5,8,18]$

According to this theory, obstruction leads to inflammation, rising intraluminal pressures, and ultimately ischemia. Subsequently, the appendix enlarges and incites inflammatory changes in the surrounding tissues, such as in the pericaecal fat and peritoneum. If untreated, the inflamed appendix eventually perforates. True appendiceal calculi (hard, noncrushable, calcified stones) are less common than appendiceal faecaliths (hard but 
crushable concretions) but have been associated more commonly with perforating appendicitis and with periappendiceal abscess. This aetiology of occlusion appears to be more common in younger individuals, in whom lymphoid tissue is more abundant than in older persons. $[1,2,5,8,18]$

Rapid distension of the appendix ensues because of its small luminal capacity and intraluminal pressures can reach 50 to $65 \mathrm{~mm} \mathrm{Hg}$. As luminal pressure increases, venous pressure is exceeded and mucosal ischemia develops. Once luminal pressure exceeds $85 \mathrm{~mm}$ $\mathrm{Hg}$, thrombosis of the venules that drain the appendix occurs and in the setting of continued arteriolar inflow, vascular congestion and engorgement of the appendix become manifest. Lymphatic and venous drainage is impaired and ischemia develops. Mucosa becomes hypoxic and begins to ulcerate, resulting in compromise of the mucosal barrier and leading to invasion of the appendiceal wall by intraluminal bacteria. Most of bacterias are gramnegative, mainly Escherichia coli (present in $76 \%$ of cases), followed by Enteroccocus (30\%), Bacteroides (24\%) and Pseudomonas (20\%).

This inflammation extends to include serosa, parietal peritoneum, and adjacent organs. As a result, visceral afferent nerve fibres that enter the spinal cord at T8 - T10 are stimulated, causing referred epigastric and periumbilical pain represented by these dermatomes. At this stage, somatic pain supersedes the early referred pain, and patients usually undergo a shifting of maximal pain to the right lower quadrant. If allowed to progress, arterial blood flow is eventually compromised, and infarction occurs, resulting in gangrene and perforation, which usually occurs after 24 and 36 hours. Anorexia, nausea, and vomiting usually follow as the pathophysiology worsens. [1,3,5]

There is strong epidemiologic evidence supporting the proposition that perforated and nonperforated appendicitis are separate entities with different pathogenesis. Patients with a short duration of symptoms had a predominantly neutrophil infiltrate that changed to a predominant lymphocytic infiltrate with evidence of granulation tissue as the duration of symptoms became longer. These findings support the contention that a mixed infiltrate of lymphocytes and eosinophils represents a regression phase of acute appendicitis. Fibrous adhesion formation and scarring of the appendix wall also have been demonstrated and are consistent with resolution of a previous attack of appendicitis. To understand this phenomenon, we need to re-examine the pathogenesis of appendicitis. [17]

Even being logical and possible to be true, this theory was not proven. In the most recent review on aetiology and pathogenesis, several studies showed that, contrary to common thinking, obstruction of the appendix is unlikely to be the primary cause in the majority of patients. An investigation that measured the intraluminal pressure in the appendix showed that in $90 \%$ of patients with phlegmonous appendicitis, there was neither raised intraluminal pressure nor signs of luminal obstruction. There were signs of obstruction of the appendiceal lumen, expressed as an elevated intraluminal pressure, in all patients with a gangrenous appendix, but not in patients with phlegmonous appendix. These data suggest that obstruction is not an important factor in the causation of acute appendicitis, although it may develop as a result of the inflammatory process. On the basis of available evidence, it is likely that there are several aetiologies of appendicitis, each of which leads to the final pathway of invasion of the appendiceal wall by intraluminal bacteria. [17]

Occasionally, patients will complain of pain that is intermittent over the course of weeks or months. Others may describe a more persistent pain lasting a similar period. At laparotomy, the appendices of these patients demonstrate histological evidence of chronic active 
inflammation or fibrosis supportive of the diagnosis of recurrent or chronic appendicitis. Recurrent and chronic forms of appendicitis also have been recognized and occur with an approximate incidence of $10 \%$ and $1 \%$, respectively. [1,3,8]

Recently, with the advent of neurogastroenterology, the concept of neuroimmune appendicitis has evolved. After a previous minor bout of intestinal inflammation, subtle alterations in enteric neurotransmitters are seen, which may result in altered visceral perception from the gut; this process has been implicated in a wide range of gastrointestinal conditions. Further work is needed to determine if the clinical entity of "neuroimmune appendicitis" truly exists, but it remains an interesting area. [7]

About $95 \%$ of serotonin in the body is in the gastrointestinal tract, located mainly in the mucosal neuroendocrine cells. Large amounts of 5-HT are present in the mucosa of the appendix where the amine is concentrated in the enterochromaffin cells of the mucosa. There are two types of neuroendocrine cells in the epithelium: enterochromaffin cells, which are found as single cells within the crypt cells, and subepithelial neuroendocrine cells, located in the lamina propria. These cells are recognized by expression of several markers, including large dense core vesicles containing serotonin and chromogranin A, and synapticlike microvesicles containing synaptophysin. 5-HT secretion from enterochromaffin cells occurs predominantly at the interstitial side and is controlled by a complex pattern of receptor-mediated mechanisms. $[19,20]$

Serotonin is involved in diverse motor, sensory, and secretory functions via its different receptors locating on epithelial cells and on submucosal and myenteric neurons. Appendixes with inflammation are markedly depleted of serotonin, in the epithelium (enterochromaffin cells) and lamina propria. [20]

Local increase in serotonin secretion in the appendix may play an important role in the pathogenesis of inflammation in the appendix. The initial event in appendicitis is thought to be luminal obstruction with various aetiologies. Once obstruction occurs, epithelial mucosal secretions increase the luminal pressure. It has been suggested that enterochromaffin cells have pressure receptors and that upon sensing luminal pressure they release 5-HT into the lamina propria. After 5-HT is released into the circulation, it is metabolized in the liver to 5-HIAA by mitochondrial monoamine oxidase, then subsequently excreted in urine $[20,21]$

Serotonin is a potent intestinal secretory agent and can cause increased fluid and electrolyte secretion via the 5-HT3 receptor. Serotonin is also a vasoconstrictor, acting through 5-HT1 and 5-HT2b receptors. By stimulating some atypical receptors, 5-HT mediates endotheliumdependent relaxing effects on the veins. In addition, through 5-HT4 receptors located in the myenteric plexus and smooth muscle, serotonin can regulate peristaltic actions in the alimentary tract. It may be postulated that local serotonin release exacerbates intraluminal secretion, venous engorgement, vasoconstriction and smooth muscle contraction, which diverts the congestive process to an inflammatory one. Abundant 5-HT3 receptors on vagal and other splanchnic afferent neurons and on enterochromaffin cells have a significant role in inducing nausea and emesis. However, a cause and effect relationship between subepithelial neurosecretory cells and appendicitis, if any, remains to be established. $[19,20,22,23,24]$

The origin of enterochromaffin cells is controversial. Several theories suggest their origin being as follows: [22] 
- $\quad$ in the amine precursor uptake and decarboxylation cell (APUD) system;

- two independent cell origins for mucin-producing cells and carcinoid cells;

- $\quad$ subepithelial neurosecretory cells (SNC) origin;

- $\quad$ bidirectional differentiation of a common cell origin;

- $\quad$ crypt cell origin derived from a population of lysozyme-containing goblet cells present in normal intestinal crypts;

- amphicrine cell origin defined as a cell in the gastrointestinal tract which contains mucus granules, zymogen granules, and endocrine secretory which contains mucus granules, zymogen granules, and endocrine secretory granules and possesses a endocrine-exocrine nature.

As it can be observed, based on the large amount of studies related to appendicitis, it is not established the pathophysiology of this disease. There is not doubt that all these phenomena are related to appendicitis and they are part of the genesis of this inflammation. However more investigations must be performed in order to understand this still mysterious disturbance.

\section{Clinical aspects}

Abdominal pain is the primary presenting complaint of patients with acute appendicitis. The diagnostic sequence of colicky central abdominal pain followed by vomiting with migration of the pain to the right iliac fossa is present in only $50 \%$ of patients. Typically, the patient describes a peri-umbilical colicky pain, which intensifies during the first 24 hours, becoming constant and sharp, and migrates to the right iliac fossa. The initial pain represents a referred pain resulting from the visceral innervation of the midgut, and the localised pain is caused by involvement of the parietal peritoneum after progression of the inflammatory process. Loss of appetite is often a predominant feature. Constipation and nausea are often present with profuse vomiting that may indicate development of generalised peritonitis after perforation but is rarely a major feature in simple appendicitis. (Table 1) $[1,2,3,5,8,18]$

\begin{tabular}{|l|c|c|}
\hline CLINICAL FINDING & ADULTS & CHILDREN \\
\hline Right lower quadrant pain & 8.4 & - \\
\hline Migration (periumbilical to right lower quadrant) & 3.6 & 1.9 to 3.1 \\
\hline Initial clinical impression of the surgeon & 3.5 & 3.0 to 9.0 \\
\hline Psoas sign & 3.2 & 2.5 \\
\hline Fever & 3.2 & 3.4 \\
\hline Pain before vomiting & 2.7 & - \\
\hline Rebound tenderness & 2.0 & 3.0 \\
\hline Rectal tenderness & - & 2.3 \\
\hline
\end{tabular}

Table 1. Accuracy (likelihood ratio) of findings from the history and physical examination in the diagnosis of appendicitis in adults and children. [1,2,3,30]

Patients with acute appendicitis usually are afebrile or have a low-grade fever. Perforation should be suspected whenever a patient's temperature exceeds $38.3^{\circ} \mathrm{C}$. If perforation does occur, periappendiceal phlegmon or abscess will result if the terminal ileum, caecum, and omentum are able to "wall off" the inflammation. Peritonitis usually develops if there is free perforation into the abdominal cavity. (Table 1) $[1,2,3,8]$ 
Acute appendicitis should not be considered as a uniform disease in all patients. Particular manifestations of this inflammation have been described in special conditions that may bring up confusing or facilitating factors to make an early and precise diagnosis.

\subsection{Pregnancy}

Appendicitis is the most common extra-uterine surgical emergency in pregnancy, with an incidence of approximately 1 in 1200 to 1500 pregnancies. Although the symptoms of acute appendicitis are similar to those in non-pregnant women, nausea, vomiting, and anorexia may be mistakenly attributed to the pregnancy, particularly in the first trimester. Fever and tachycardia may not be present during pregnancy. Right upper quadrant pain, uterine contractions, dysuria, and diarrhoea can also be present. $[3,4]$

The diagnosis is often delayed due to the high prevalence of background gastrointestinal complaints, as well as difficulties in the interpretation of physical and laboratory work-up. Anatomic alterations in the location of appendix due to the expanding uterus and physiologic changes observed in pregnancy, such as leukocytosis, can hinder the diagnosis. In addition, there is generally a greater reluctance to operate unnecessarily on a gravid patient. [25,26]

Considering differential diagnosis, both obstetrical and gynaecological conditions can present with abdominal pain and mimic appendicitis. Non-obstetrical/non-gynaecological conditions include gastroenteritis, urinary tract infections, pyleonephritis, cholecystitis, cholelithiasis, pancreatitis, nephrolithiasis, hernia, bowel obstruction, carcinoma of the large bowel, mesenteric adenitis, and rectus hematoma, pulmonary embolism, right-lower-lobe pneumonia, and sickle cell disease. Gynaecologic and obstetric conditions include ovarian cyst, adnexal torsion, salpingitis, abruptio placenta, chorioamnionitis, degenerative fibroid, ectopic pregnancy, preeclampsia, round ligament syndrome, and preterm labour. [27] Laboratory evaluation may not be helpful and cannot be relied on. Leukocytosis in pregnancy can be as high as 16,000 cells/ $\mathrm{ml}$ and still considered a normal variant and not a clear indicator of appendicitis. During labour, it may rise to 30,000 cells/ml, and not all pregnant patients with appendicitis have leukocytosis. It is not a reliable marker, as up to $33 \%$ of cases may have a leukocyte count greater than $15,000 / \mathrm{mm}$. To confirm the diagnosis, ultrasound has shown to be highly sensitive and specific although to a lesser degree after a gestational age of 35 weeks due to technical difficulties. This non-invasive procedure should be considered first in working up suspected acute appendicitis. [7,27]

Incidence rates in the first trimester range from $19 \%$ to $36 \%$, in the second trimester, range from $27 \%$ to $60 \%$ and in the third trimester, range from $15 \%$ to $59 \%$. Due to the lack of specificity of the preoperative evaluation; the pathologic diagnosis of appendicitis is confirmed in only $30 \%$ to $50 \%$ of cases, considering first trimester yields a greater accuracy. Patients in the second and third trimester of pregnancy often have pain in the right upper quadrant or flank, with biliary colic and pyelonephritis representing common misdiagnoses. $[7,25,27]$

The risk of delay in diagnosis is associated with a greater risk of complications such as perforation, infection, preterm labour, and risks of fetal or maternal loss. Maternal mortality has been reported from none to $2 \%$. An unruptured appendix carries a fetal loss of $1.5 \%$ to $9 \%$, while this rate increases up to $36 \%$ with perforation. The risk of fetal loss associated with appendicitis in pregnancy is $33 \%$ in the first trimester, $14 \%$ in the second trimester and none in the third trimester. $[7,27]$ 
Accordingly, the incidence of perforation during pregnancy is as high as $25 \%$ to $55 \%$ compared with $4 \%$ to $19 \%$ of the general population. With early surgical intervention, morbidity and mortality rates are similar to those of the non-pregnant patient. Foetal mortality rates, however, are as high as $35 \%$ in patients with perforation and peritonitis, making early diagnosis and surgery imperative. [1,26,27]

Tests that are used to improve diagnostic performance include compression graded ultrasonography, magnetic resonance imaging (MRI), and computed tomography (CT). Radiation exposure also is an important factor in managing pregnant patients. Fetal exposure from abdominal multidetector $\mathrm{CT}$ performed in the first trimester may double the likelihood of childhood cancer (from 1 to 2 in 600). Consequently, ultrasound is usually the first study attempted. Compression graded ultrasonography has long been the preferred test and is indicated first in the work-up of pregnant patients with suspected appendicitis since there is no exposure to ionizing radiation. However, ultrasonography is operator dependent and can be difficult to interpret due to obesity, a retrocaecal appendix, or a gravid uterus. Accordingly, the reported diagnostic performance of ultrasonography in pregnancy varies widely. Although high accuracy of ultrasound in pregnancy has been reported, several factors limit its usefulness. The appendix may be displaced from its expected location by the gravid uterus. The enlarged uterus also may make graded compression difficult.

Due to this variable performance, the use of MRI and CT in pregnant women with suspected appendicitis has recently gained importance and is advocated by some authors after normal/inconclusive ultrasonography result. MR imaging has emerged recently as a useful second-line technique and seems to have a high accuracy and low failure rate. The use of MR imaging eliminates radiation exposure of the foetus, avoids the operator dependency of ultrasound, and facilitates rendering alternative diagnoses, such as ovarian torsion or renal obstruction. However MRI is not free of risks including the potential biological effects of the static and time-varying magnetic fields, the heating effects of the radiofrequency pulses, and the acoustic noise generated by the spatial encoding gradients. $[18,25,28]$

When appendicitis is suspected, timely obstetric as well as a general surgical consult is necessary. Assessment for open laparotomy is dependent on gestational age since the appendix progressively relocates. Pregnancy is not considered to be a contraindication for laparoscopic approach to appendectomy.

Laparoscopic surgery in the pregnant patient has not been broadly accepted in the latter second and third trimester due to the concern regarding fetal wastage, the effects of carbon dioxide on the developing foetus and the long-term effects of this exposure. Laparoscopy procedures take approximately $50 \%$ longer with conflicting studies showing decreased length of stay and hospitalization. Questions arise regarding the risk for decreased uterine blood flow due to increased intraabdominal pressures from insufflation and the possibility of fetal carbon dioxide absorption. Use of nitrous oxide pneumoperitoneum has been advocated although technical difficulties arise with the gravid uterus. Blind placement of the Veress needle, or primary port, has resulted in puncturing and subsequent pneumoamnion. [29]

\subsection{Children}

Appendicitis is the most common surgical disease of the abdomen in children. Paediatric appendicitis varies considerably in its clinical presentation, contributing to delay in diagnosis and increased morbidity. The methods of diagnosis and treatment of appendicitis also vary significantly among clinicians and medical canters according to the patient clinical 
status, the medical centre's capabilities, and the physician's experience and technical expertise. Recent trends include the increased use of radiologic imaging, minimally invasive and nonoperative treatments, shorter hospital stays, and home antibiotic therapy. Little consensus exists regarding many aspects of the care of the child with complicated appendicitis. [1]

In adults, right lower quadrant pain and migration of pain from the umbilicus area to the right lower quadrant are the symptoms that best predict appendicitis, whereas the absence of pain before vomiting greatly reduces the likelihood of appendicitis. The accuracy of history and physical examination findings is somewhat different in children. Vomiting, rectal tenderness, rebound tenderness, and fever are more helpful (greater positive likelihood ratio) in children than in adults, whereas right lower quadrant tenderness is somewhat less helpful. (Table 1) [1,2,3,30,31,32]

Emergency department evaluation of children with acute appendicitis presents a particular challenge. The rate of misdiagnosis is as high as $57 \%$ in children under the age of 6 years with perforation rates as high as $90 \%$ in some series. Common misdiagnoses include acute gastroenteritis, viral respiratory syndromes, and urinary tract infection. Children are more likely to complain of diffuse rather than referred or localized pain. Those initially misdiagnosed tend to have a higher incidence of vomiting, diarrhoea, constipation, dysuria, and respiratory symptoms accounting for physician bias against the correct diagnosis.

Perforation is most common in young children, with rates as high as $82 \%$ for children under age 5 years and up to $100 \%$ in one-year-olds. A high index of suspicion combined with a low threshold for surgical consultation minimizes the risk of missed diagnosis. The high perforation rate in young children is largely due to the fact that they are less communicative than older children, and their caregivers often assume that their child has gastroenteritis based on the common accompanying symptoms of anorexia, vomiting, diarrhoea, and fever. $[15,30,31]$

The Alvarado score has been prospectively validated in several populations of children and adults. Variations include the modified Alvarado score, in Paediatric Appendicitis Score, which substitutes right lower quadrant pain with cough, hopping, or percussion for rebound tenderness. However, these modifications have not been shown to perform better than the original Alvarado score. (Tables 1 and 2) [12,31]

\begin{tabular}{|l|c|}
\hline CLINICAL FINDING & POINTS \\
\hline Migration of pain to the right lower quadrant & 1 \\
\hline Anorexia & 1 \\
\hline Nausea and vomiting & 1 \\
\hline Tenderness in the right lower quadrant & 2 \\
\hline Rebound pain & 1 \\
\hline Elevated temperature $\left(\geq 99.1^{\circ} \mathrm{F}=37.3^{\circ} \mathrm{C}\right)$ & 1 \\
\hline Leukocytosis $\left(\geq 10,000\right.$ white blood cells per $\left.\mathrm{mm}^{3}\right)$ & 2 \\
\hline Shift of WBC count to the left $(>75$ percent neutrophils $)$ & 1 \\
\hline
\end{tabular}

*Patients with a score of $\geq 7$ points have a high risk of appendicitis.

*Patients with a score of $<5$ points have a very low risk of appendicitis.

Table 2. Alvarado score for the diagnosis of appendicitis. [12,33] 
The clinical condition of a child at the time of diagnosis can vary substantially across a spectrum of severity, from minimally symptomatic children with normal laboratory studies to those with bowel obstruction and frank septic shock. Surgery is indicated in all cases. Non-operative treatment should not be proposed in children due to higher risk of severe complications. Even in children the laparoscopic approach has been preferred not only to confirm the diagnosis but also to treat the patient. [31]

\subsection{Elderly}

Patients at the extremes of the age spectrum can present diagnostic difficulty because of non-specific presentation, often with subtle clinical signs. Elderly people may present with confusion. A high index of suspicion for acute appendicitis is needed in such patients. Older patients present later, have more subtle signs and symptoms, and often treat themselves with analgesics before their presentation. [1]

Those at the extremes of age appear to be at highest risk of perforation from delayed diagnosis. The proportion of perforations has a relation to age, with a high proportion in older people. Misdiagnosis commonly exceeds $50 \%$, with perforation rates that range from $40 \%$ to $70 \%$. Delay because of atypical presentation and age-related differences in the progression of the inflammation have been proposed as explanations. The high proportion of perforated appendicitis in older patients is therefore the consequence of the relatively low incidence rate of non-perforated appendicitis at these ages and is not associated with an increased incidence rate of perforations. [15]

The inflammatory process is less intense than in the youth and occurs later. On the other hand, the appendicitis in the elders is mainly due to ischemic phenomena with early necrosis and perforation. Thus these patients present early appendiceal perforation, before the inflammatory process is developed. The less intense inflammation and the ischemic process are responsible for the poor abdominal symptoms and laboratorial or imaginological findings.

Elderly patients may present with vague abdominal pain or even no pain at all. With the age-related increased risk of other pathologic entities, such as diverticulitis and cancer, the diagnosis of appendicitis is often delayed up to 72 hours. [2]

Patients over the age of 55 years underwent laparotomy on average two days later than youth people and with higher risk of severe complications. For these reasons and considering the elder people have less organic reserve, the surgery is indicated precociously. The laparoscopy is indicated to confirm the diagnosis and perform the appendiceal withdrawn. Even when the appendix is perforated, the laparoscopy is the best procedure since the patients does not present abdominal multiple adhesions provoked by previous surgeries. Due to pneumoperitoneum, this approach should be carefully considered in patients with severe heart and pulmonary disturbances.

\subsection{Haematological diseases}

Patients suffering of some haematological diseases, such as drepanocitosis, spherocytosis, neutropenia, leukaemia and thrombocitopenic purpura present a higher incidence of acute appendicitis. It is not established the pathophysiology of these conditions related to the development of appendicitis.

In fact, inflammation is not the main finding in these cases. Similarly to elder patients in the presence of haematological diseases the appendix present vascular obstructions with ulcers 
spread in its mucosa. Due to ischemia, transmural necrosis is frequent and perforation occurs earlier and most frequently than in the general population. Thus a special attention to the appendix should be considered when these patients complain abdominal pain, even without the characteristics events found in the classical appendicitis provoked by inflammatory phenomena.

The surgical treatment should be considered even before the confirmation of the diagnosis, when the patient persists with pain or his general state worsens. In all cases the appendix should be removed.

\subsection{Oncological diseases}

Patients undergoing chemotherapy for solid tumours or leukaemias also present a clinical dilemma. During the induction of therapy, many patients experience abdominal pain. Although a majority of these patients have self-limiting symptoms, others develop progressive abdominal pain. Among the most common identifiable source of pain is acute typhlitis, inflammation of the terminal ileum and caecum.

Abdominal pain is a common complication of chemotherapy, almost unique to children, and is usually treated non-surgically. Differentiation from acute appendicitis, however, is extremely difficult, with a documented error rate in these patients of greater than $37 \%$. In order to avoid the unacceptably high morbidity and mortality associated with the perioperative complications of perforation, exploration has been recommended in these patients with early signs suggestive of local peritonitis.

All these patients are immunocompromised and the mortality of complicated appendicitis is higher than in the general people. Thus the appendectomy should be precociously indicated when acute appendicitis is clinically suspected.

\subsection{AIDS}

Patients with AIDS present a higher incidence of appendicitis than the general population. It is not established this complication is due to local infection in this immunocompromised group or is consequent to ischemic factors.

In most of patients (91\%) the pain is localized in the right flank, but $24 \%$ of them complain general abdominal pain since the beginning. Anorexia is found in $90 \%$ of patients. Nausea and vomiting are present in $41 \%$ and intensification of diarrhoea occurs in $22 \%$ of these cases.

Immunocompromised patients are at particular risk of developing complications from delayed diagnosis. These patients present with signs and symptoms of acute appendicitis; however, there may be a delay in seeking evaluation because pain tolerance is higher or analgesic drugs may be readily available.

Patients with the acquired immunodeficiency syndrome (AIDS) commonly have symptoms in the gastrointestinal system. Opportunistic infections such as cryptosporidiosis, cytomegalovirus colitis, Mycobacterium avium intracellulare, and lymphoma and Kaposi's sarcoma may present similarly to acute appendicitis, making the diagnosis difficult. The perforation rate is approximately $40 \%$ in this population and recommends early surgical intervention. [1]

\section{Diagnosis}

The diagnosis of appendicitis can be challenging even in the most experienced of clinical hands. The diagnosis of acute appendicitis is predominantly a clinical one. An accurate 
diagnosis is important to prevent unnecessary surgery and avoid complications. The probability of appendicitis depends on patient age, setting, and symptoms. The probability of appendicitis depends on patient age, setting, and symptoms. [30,33]

The Alvarado score, originally described in 1986, is the most widely reported scoring system for acute appendicitis. This score alone is not accurate enough to diagnose or exclude appendicitis. (Table 2) However, it provide a useful starting point by identifying children and adults at low and high risk of appendicitis. Most patients at low risk can be observed without further diagnostic study, but they may benefit from further diagnostic testing, including imaging studies; and patients at high risk should receive urgent surgical evaluation. Five percent of patients with scores of 3 or less have appendicitis, $36 \%$ of patients with scores between 4 and 6 have appendicitis, and $78 \%$ of patients with scores of 7 or higher have appendicitis. [12,33]

No specific diagnostic test for appendicitis exists, but the judicious use of simple urine and blood tests, particularly inflammatory response variables, should allow exclusion of other pathologies and provide additional evidence to support a clinical diagnosis of appendicitis. Scoring systems and algorithms have been proposed to aid the diagnosis of acute appendicitis but have not been widely used. (Table 2,3) [7]

The overall accuracy for diagnosing acute appendicitis is approximately $80 \%$, which corresponds to a mean false-negative appendectomy rate of $20 \%$. Diagnostic accuracy varies by sex, with a range of $78 \%-92 \%$ in male and $58 \%-85 \%$ in female patients. These differences reflect the fact that appendicitis may be extremely difficult to diagnose in women of childbearing age, because symptoms of acute gynaecologic conditions such as pelvic inflammatory disease may manifest similarly. This diagnostic problem has led to false-negative appendectomy rates as high as $47 \%$ in female patients aged 10-39 years. (Table 3)

\begin{tabular}{lcc}
\hline \hline SYMPTOMS AND SIGNS & SENSIBILITY & SPECIFICITY \\
\hline Hyporexia & $58 \%$ to $91 \%$ & $37 \%$ to $40 \%$ \\
Nauseas and vomitings & $40 \%$ to $72 \%$ & $45 \%$ to $69 \%$ \\
Diarrhoea & $9 \%$ to $24 \%$ & $58 \%$ to $65 \%$ \\
Fever & $27 \%$ to $74 \%$ & $50 \%$ to $84 \%$ \\
Rebound pain & $80 \%$ to $87 \%$ & $69 \%$ to $78 \%$ \\
Leukocytosis & $42 \%$ to $96 \%$ & $53 \%$ to $76 \%$ \\
C-reactive-protein & $41 \%$ to $48 \%$ & $49 \%$ to $57 \%$ \\
\hline \hline
\end{tabular}

Table 3. Sensibility and specificity of symptoms and signs on the diagnosis of acute appendicitis. $[7,30,33]$

\subsection{Anamnesis}

For the majority of patients who present to the emergency department with acute appendicitis, abdominal pain will be their chief complaint. Those presenting within the first few hours of onset often describe a poorly defined, constant pain referred to the periumbilical or epigastric region. Nausea, vomiting, and anorexia occur in varying degrees, though are usually present in more than $50 \%$ of cases in all studies. With disease progressing as previously outlined, pain becomes well defined and localizes in the right lower quadrant near McBurney's point. [2] 
This classic presentation of acute appendicitis occurs in only one half to two thirds of all patients. Accordingly, the clinician should not consider it the sine qua non for the diagnosis of acute appendicitis. A failure to recognize other presentations of acute appendicitis will lead to a delay in diagnosis and increased patient morbidity. Patients with a retrocaecal appendix or those presenting in the later months of pregnancy may have pain limited to the right flank or costovertebral angle. Male patients with a retrocaecal appendix may complain of right testicular pain. Pelvic or retroileal locations of an inflamed appendix will refer to the pelvis, rectum, adnexa, or rarely, the left lower quadrant. Subcaecal and pelvic suprapubic pain and urinary frequency may predominate.

\subsection{Physical examination}

By far, the most likely physical finding is abdominal tenderness, which occurs in over $95 \%$ of patients with acute appendicitis. Patients often find the right lateral decubitus position with slight hip flexion as the position of maximal comfort. The abdomen is generally soft with localized tenderness at or about McBurney's point. [1]

The patient is often flushed, with a dry tongue and an associated faetor oris. Temperature elevations greater than $1^{\circ} \mathrm{C}$ are rare until appendiceal inflammation has progressed transmurally or perforation has occurred. The presence of pyrexia (up to $38^{\circ} \mathrm{C}$ ) with tachycardia is common. A difference between axillary and rectal temperature higher than $1^{\circ} \mathrm{C}$ indicates pelvic inflammation that may be due to appendicitis or other pelvic inflammation.

Abdominal examination reveals localised tenderness and muscular rigidity after localisation of the pain to the right iliac fossa. Rebound tenderness is present, but should not be elicited to avoid distressing the patient. Patients often find that movement exacerbates the pain, and if they are asked to cough the pain will often be localised to the right iliac fossa. Diarrhoea may be present as a result of irritation of the rectum.

Percussion tenderness, guarding, and rebound tenderness are the most reliable clinical findings indicating a diagnosis of acute appendicitis. Bowel sounds vary and are more likely to be diminished or absent with advanced inflammation or perforation. Voluntary muscle guarding in the right lower quadrant is common and usually precedes localized rebound tenderness. The follow signs of acute appendicitis are the mostly described, but they occur in less than $10 \%$ of patients with acute appendicitis, and their absence should not prevent the examiner from establishing an accurate diagnosis: [1,2,7]

- $\quad$ Blumberg's rebound pain; (Figure 2A)

- Rovsing's sign - pain that is referred to the area of maximal tenderness during percussion or palpation of the left lower quadrant; (Figure 2B)

- $\quad$ a positive psoas (right lower quadrant pain with extension of the right hip); (Figure 2C)

- obturator (right lower quadrant pain with flexion and internal rotation of the right hip) sign depends on the location of the appendix in relation to these muscles and the degree of appendiceal inflammation. (Figure 2D)

Findings on per rectal and vaginal examination may be normal, although tenderness to the right may be present particularly in a pelvic appendix. Tenderness on rectal examination may be suggestive but is not diagnostic of appendicitis. However, the utility of rectal examination in patients with acute appendicitis has been brought into question. Repeated rectal examinations, especially in children, are burdensome and offer little diagnostic value. In patients with signs and symptoms consistent with a classic presentation of acute appendicitis, rectal examination offers little toward furthering diagnostic accuracy. Rectal examination should be reserved for those in whom pelvic or uterine pathology is suspected, or in atypical presentations that suggest pelvic or retrocaecal appendicitis. [1] 

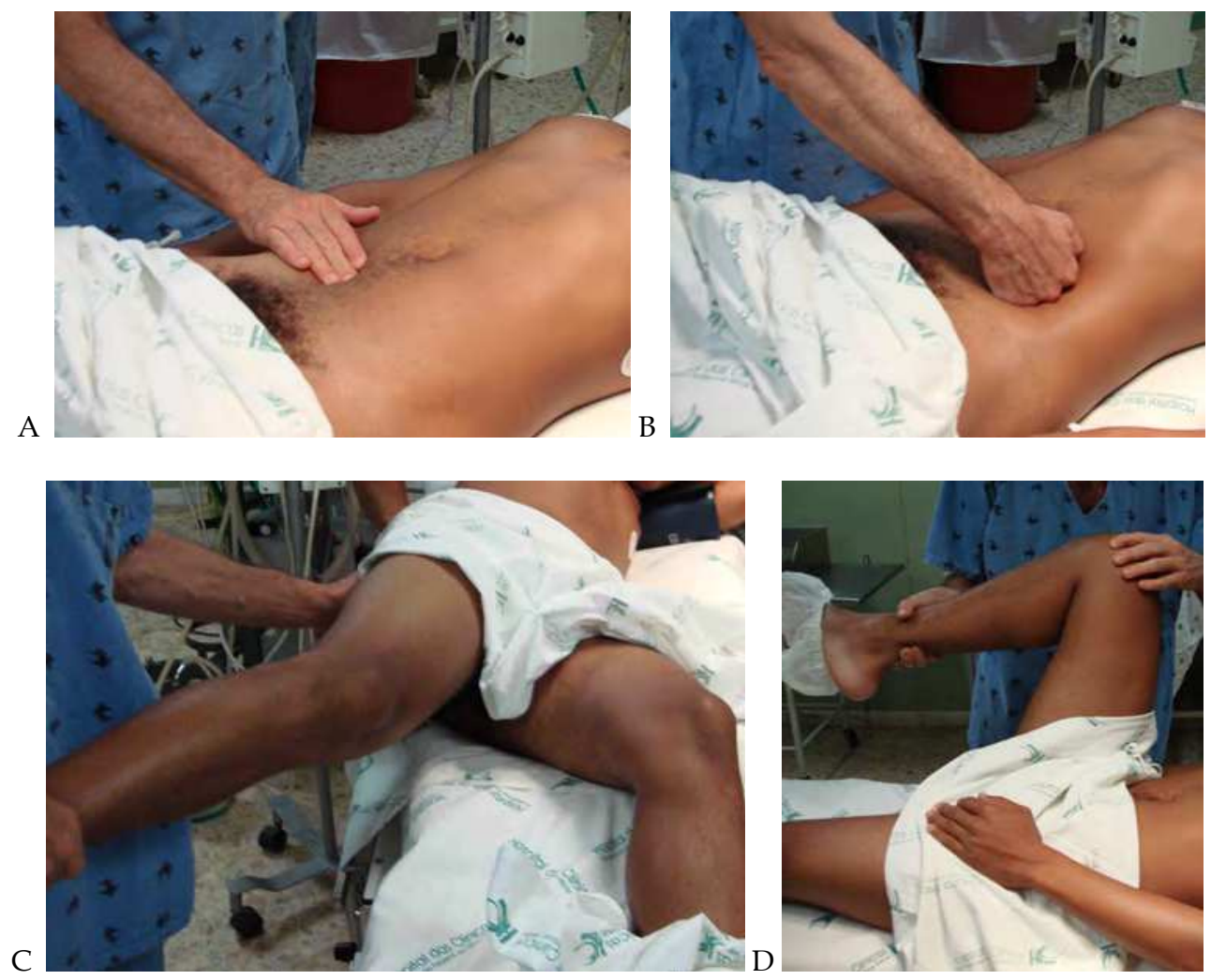

Fig. 2. Physical exam of a patient with right abdominal pain.

A) Blumberg's sign. B) Rovsing's sign. C) Psoas sign. D) Obturator sign.

\subsection{Laboratorial findings}

There is not a single laboratory marker for discriminating acute appendicitis from other causes of abdominal pain. Laboratory data upon presentation usually reveal a mildly elevated leukocytosis with a left shift. The white blood cell (WBC) count is elevated (greater than $10,000 / \mathrm{mm}^{3}$ ) in $70 \%$ to $90 \%$ of patients with acute appendicitis. Likewise, neutrophilia greater than $75 \%$ will occur in the majority of cases. Similar results have been found in paediatric elderly, and pregnant patients with acute appendicitis. This is not true for elderly, immunocompromised patients, with conditions such as malignancy or AIDS; leukocytosis is observed in only $12 \%$ and $14 \%$ of such patients. [1]

The WBC count is elevated in many other intra-abdominal disease processes, however, both surgical (i.e., cholecystitis, intestinal obstruction) and nonsurgical (i.e., gastroenteritis, pelvic inflammatory disease). Although statistically significant differences exist between WBC elevation observed in appendicitis and that observed in mesenteric adenitis, gastroenteritis, and abdominal pain of unknown cause, the usefulness of these differences in the evaluation of any individual patient is minimal. 
Measurement of C-reactive protein (CRP), an acute phase reactant, has been studied. The normal value of $C$ reactive protein is $<15 \mathrm{mg} / 1$ and in acute appendicitis is $>25 \mathrm{mg} / 1$. In presence of gangrenous appendicitis is $>55 \mathrm{mg} / 1$ and of perforated appendicitis is $>66 \mathrm{mg} / \mathrm{l}$. An elevated CRP appears to have a sensitivity of $47 \%$ to $75 \%$ and specificity of $56 \%$ to $82 \%$ in acute appendicitis. The CRP is most likely to be elevated in appendicitis if symptoms are present for more than 12 hours. Interestingly, the combination of an elevated CRP, elevated WBC, or neutrophilia greater than $75 \%$ improves the sensitivity to $97 \%$ to $100 \%$ for the diagnosis of acute appendicitis. Thus, for patients with normal values for all three studies, the likelihood of acute appendicitis would be low.

It has been shown that monitoring the blood level of serotonin or 5-hydroxytryptamine $(5 \mathrm{HT})$ is a useful test in the diagnosis of appendicitis. During inflammation, enterochromaffin cells in the appendix secrete serotonin, and 5-hydroxyindoleacetic acid (5-HIAA), a serotonin metabolite excreted in urine, has been found to be elevated in patients presenting with acute appendicitis. Serotonin is one of the key signalling molecules in the gut. Plasma serotonin rapidly changes to 5-hydroxy-indole-acetic acid in the liver. Measuring the urinary level of this metabolite is a reliable test especially in the early diagnosis of inflammation in appendicitis. An early study revealed plasma 5-HT to have a sensitivity of $58 \%$ to $98 \%$ and $48 \%$ to $100 \%$ specificity in adults within the first 48 hours of symptoms, suggestive of acute appendicitis. However, there was also a high correlation between urinary 5-HIAA levels and diarrheal illnesses, confounding the interpretation of 5-HIAA levels in patients presenting with abdominal pain and diarrhoea. In addition, gangrenous appendices had similar urinary 5-HIAA levels to normal appendices, thought to arise from the destruction of enterochromaffin cells in gangrenous cases. $[19,20,21]$

Several studies have demonstrated significant increases in other inflammatory markers, such serum interleukin 6 , and serum phospholipid $A_{2}$, in cases of acute appendicitis. The low specificity of many of these laboratory markers and high false-positive and negative rates prevent useful interpretation of them in discriminating acute appendicitis. Pregnancy test should also be considered in special cases, to exclude pregnancy. Cultures of the peritoneal fluid during appendectomy have been shown to be of no benefit. [2, $14,21]$

The urinalysis is abnormal in $19 \%$ to $40 \%$ of patients with acute appendicitis. Women have a higher incidence of abnormal urinalysis than men in acute appendicitis. Abnormalities include mild pyuria, bacteriuria, and haematuria. However, the presence of more than 30 red blood cells or more than 20 WBCs should cause the clinician to consider urinary tract disease in the differential diagnosis.

\subsection{Imaginological findings}

Imaginological investigations should be done only in patients in whom a clinical and laboratorial diagnosis of appendicitis cannot be made. The impact of the introduction of imaging techniques on the negative appendectomy rate is unclear. A longitudinal study has suggested that despite the introduction of ultrasonography and computed tomography scanning the rates of negative appendectomy have remained unchanged. However, other studies have evaluated the use of ultrasonography and computed tomography, and both showed a decrease in the number of unnecessary admissions and appendectomies. (Table 4) $[7,8]$ 


\begin{tabular}{|c|c|c|c|c|}
\hline \multirow[t]{2}{*}{ EXAMS } & \multirow[t]{2}{*}{ SENSIBILITY } & \multirow[t]{2}{*}{ SPECIFICITY } & \multicolumn{2}{|c|}{ PREDICTIVE VALUES } \\
\hline & & & POSITIVE & NEGATIVE \\
\hline Abdominal radiography * & $97.05 \%$ & $85.33 \%$ & $78.94 \%$ & $98.08 \%$ \\
\hline Ultrasound & $44 \%-90 \%$ & $47 \%-95 \%$ & $89 \%-94 \%$ & $89 \%-97 \%$ \\
\hline Computed tomography & $72 \%-97 \%$ & $91 \%-99 \%$ & $92 \%-98 \%$ & $95 \%-100 \%$ \\
\hline Scintigraphy & $91 \%-98 \%$ & $91 \%-99 \%$ & & \\
\hline
\end{tabular}

* Faecal loading image in the caecum.

Table 4. Accuracy of the images for the diagnosis of acute appendicitis. $[7,8,35,36,37]$

A

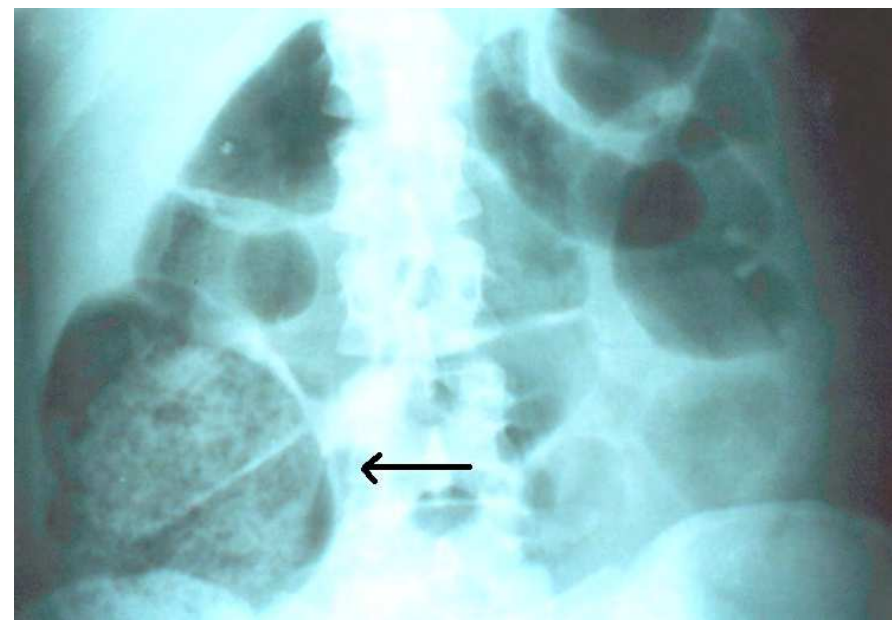

B

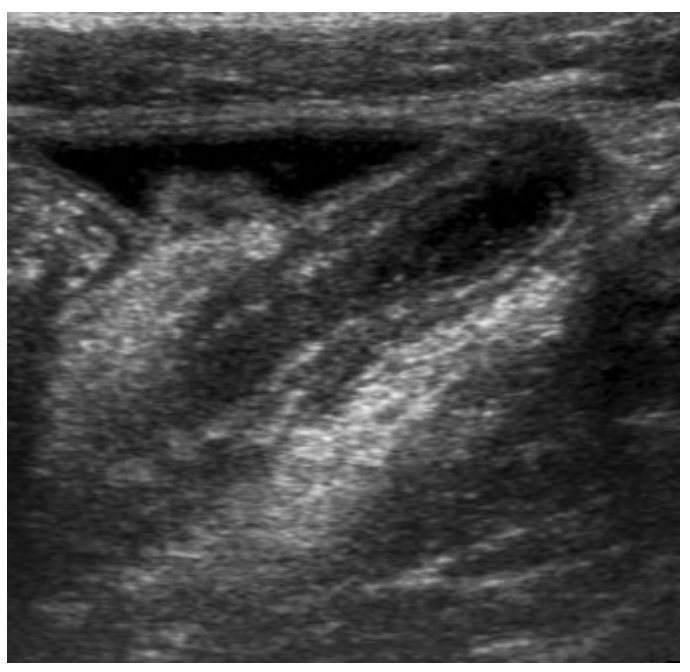


C
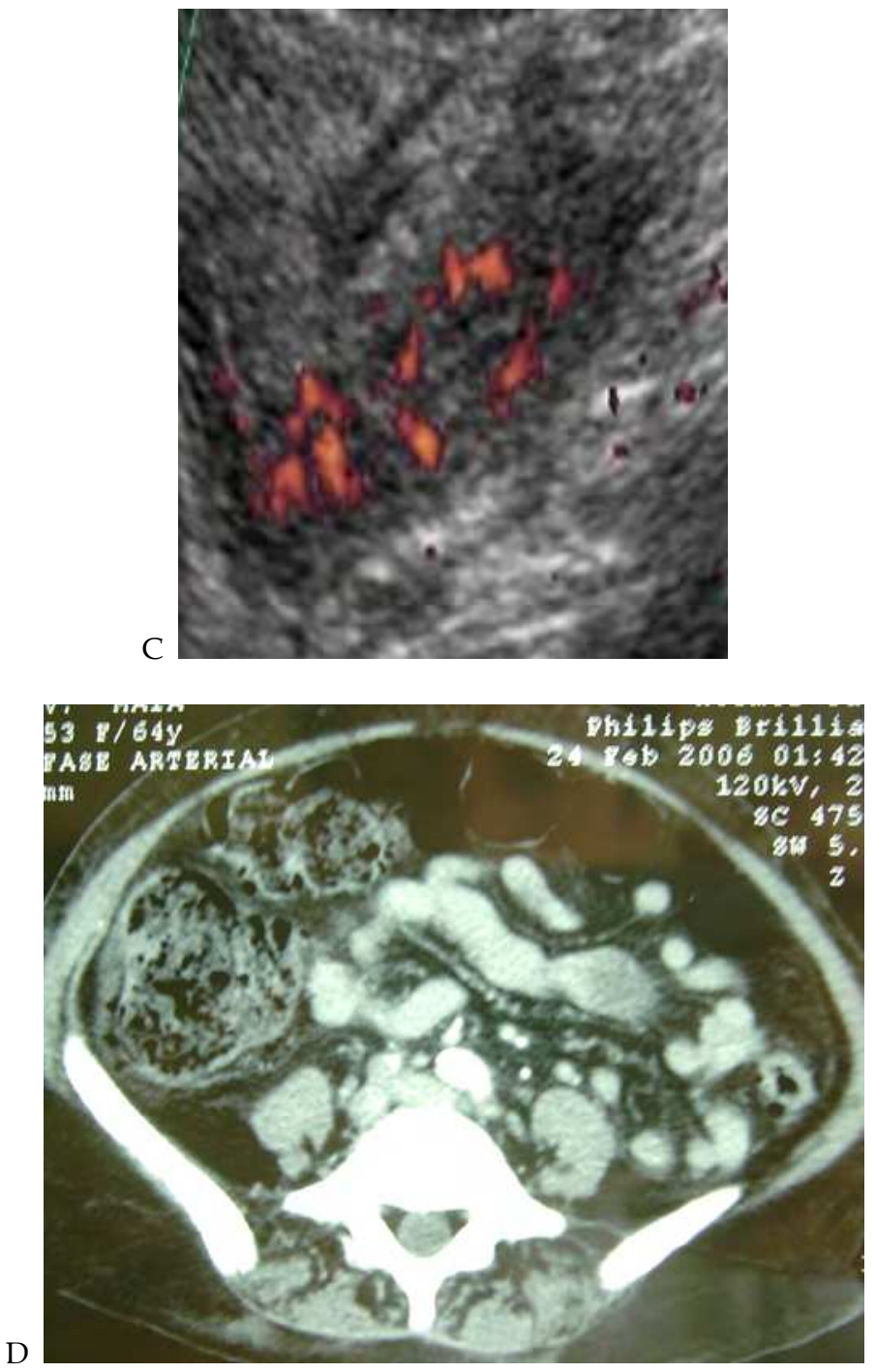

Fig. 3. Abdominal images of appendicitis.

A) Abdominal plain radiography showing distension of the caecum with faecal loading image.

B) Abdominal ultrasound showing an enlarged appendix with a thick wall.

C) Doppler ultrasound showing an inflamed appendix

D) Computed tomography of a patient with appendicitis. Observe the faecal loading in the caecum.

\subsubsection{Radiography}

Plain abdominal radiographs are abnormal in $24 \%$ to $95 \%$ of patients with appendicitis, depending on the method of the study. Radiographic signs suggestive of appendicitis 
include appendiceal faecalith; gas in the appendix; air-fluid levels or distension of the terminal ileum, caecum, or ascending colon (signs of localized paralytic ileum); loss of the caecal shadow; blurring or obliteration of the right psoas muscle; rightward scoliosis of the lumbar spine; density or haziness over the right sacroiliac joint; and free intraperitoneal air or fluid. Of these, localised ileus appears to be the most common radiographic finding. Although much is made of the presence of localized adynamic ileum, a calcified faecalith (appendicolith), deformity of the caecum and increase in soft tissue density in the lower quadrant, they are present in only a minority of patients with acute appendicitis.

A calcified appendicolith is visualized on an abdominal film in $13 \%$ to $22 \%$ of patients with acute appendicitis; however, the likelihood of perforation has been shown to be significant $(45 \%$ to $100 \%)$ if this radiographic finding is visualized. Similarly, nonspecific findings of an ileum may also be identified. None of the above radiographic signs are diagnostic or specific for appendicitis and have been observed in $38 \%$ to $60 \%$ of patients without appendicitis. (Table 5) [1,2,34,35,36,37]

In presence of acute pain, abdominal plain abdominal radiography is relevant and helpful, but little significance is attached to this exam in appendicitis. In fact the radiological signs described in the literature are not constant and none of them is specific for acute appendicitis. [35,36,37]

Since 1999, we have studying a new radiological sign, characterized by faecal loading image in the caecum. In a study, with 460 patients with confirmed appendicitis, we verified this radiological sign has a sensitivity of $97 \%$ and a specificity of $85 \%$ when compared with other inflammatory conditions of the right abdomen, such as cholecystitis, pelvic inflammatory diseases and nephrolithiasis. Another important finding is the negative predictive value that is $98 \%$. Thus in the absence of faecal loading image in the caecum, the possibility of acute appendicitis is $1 \%$. This sign disappears during the first day after appendectomy in $94 \%$ of patients. (Figure $3 \mathrm{~A}$ ) [35,36,37]

This sign seems to be due to the caecal localised ileum, provoked by the inflammatory process. The caecal content is storaged and cannot be conducted to the right colon since little movement occurs in the caecum. This condition lead to enlargement of the caecum and presence of faecal loading identified at the plain abdominal radiography. (Figure 3A) $[35,36,37]$

\begin{tabular}{lc}
\hline \hline RADIOGRAPHIC SIGNS & SENSIBLITY (\%) \\
\hline Faecal loading image in the caecum & 97,05 \\
Localized adynamic ileum & 15 to 55 \\
Image of increasing in soft tissue density & 12 to 33 \\
Image of air inside the appendix & $<2$ \\
Appendicoliths & 7 to 22 \\
Lumbar scoliosis & 1 to 14 \\
Disappearance of caecal image & 1 to 8 \\
Deformity of the caecum & 4 to 5 \\
\hline \hline
\end{tabular}

Table 5. Sensibility (percentage) of radiographic findings on diagnosis of acute appendicitis. $[1,2,34,35,36,37]$ 


\subsubsection{Ultrasound (US)}

Puylaert proposed the sonographic graded compression technique for diagnosis of appendicitis in 1986. US is rapid, non-invasive, inexpensive, and requires no patient preparation or contrast material administration. Because US involves no ionizing radiation and excels in the depiction of acute gynaecologic conditions, it is recommended as the initial imaging study in children, in young women, and during pregnancy. $[8,38,39]$

Although operator skill is an important factor in all US examinations, it has particular importance in the examination of the patient with right-lower-quadrant pain. The learning curve required to develop the technique for scanning the right lower quadrant is considerable, and there are many pitfalls to be aware of. Nonetheless, the criteria for the USbased diagnosis of acute appendicitis are well established and reliable. In experienced hands, US has reported sensitivities of $75 \%$ to $90 \%$, specificities of $86 \%$ to $100 \%$, accuracies of $87 \%$ to $96 \%$, positive predictive values of $91 \%$ to $94 \%$, and negative predictive values of $89 \%$ to $97 \%$ for the diagnosis of acute appendicitis. [3,8,14,18,38,39,40]

US examination of the patient suspected to have appendicitis should include a thorough evaluation of both the abdomen and the pelvic organs. In women in whom the answer is not evident after the performance of these two examinations, endovaginal US should be added. This is of particular importance if one considers the overlap in the symptoms of appendicitis with those of gynaecologic disease in women in the childbearing years. A gynaecologic explanation for the symptoms may be evident on the endovaginal images. Conversely, the appendix may have a pelvic location, in which case it may be seen clearly on the endovaginal image when it is not evident on the suprapubic image. [8]

The specific US approach to the right lower quadrant should include graded compression US. Putting the patient in left lateral decubitus position may be helpful in visualizing a retrocaecal appendix. Normal and gas-filled loops of gut will be either displaced from the field of view or compressed between the layers of musculature of the anterior and the posterior abdominal walls. In contrast, abnormal loops of gut, or the obstructed appendix, will be non-compressible and optimally seen on the graded compression image. $[8,18,38,39,40]$

The appendix appears on ultrasound as a lamellated, elongated, blind-ending structure. Unlike normal bowel, the inflamed appendix is fixed, non-compressible, and appears round on transverse images. Measurements of appendix are performed with full compression. Traditionally, the diagnosis of appendicitis is made when the diameter of the compressed appendix exceeds $6 \mathrm{~mm}$ In contrast, the thick-walled and non-compressible appendix, maintained in a fixed position by the compressing transducer, will show circumferential colour when inflamed. Appendiceal perforation can be diagnosed when the appendix demonstrates irregular contour or when periappendiceal fluid collections are identified. Appendicoliths are seen in $30 \%$ of appendicitis cases and may confer a higher risk of perforation. (Figure 3B) $[8,38,39,40]$

\subsubsection{Doppler Ultrasound}

The addition of colour Doppler US also is of benefit in the evaluation of inflammatory conditions of the intestinal tract. The activity of inflammation is proportional to the amount of colour signal detected within the gut wall. The normal gut is thin walled and compliant and frequently shows peristaltic activity. Hence, the detection of colour Doppler ultrasound signals from the normal gut is extremely difficult. $[8,40]$

Doppler examination usually reveals increased vascularity in and around the acutely inflamed appendix. Doppler examination is useful as an adjunct sign of appendicitis when 
the appendiceal measurement is equivocal, in which it is uncertain as to whether the imaged appendix is normal or inflamed. When increased flow is seen, it is a sensitive sign of appendicitis (reported sensitivity of $87 \%$ ), but blood flow decreases in advanced inflammation, when intraluminal pressures exceed perfusion pressures. Doppler signal is diminished when the appendix is gangrenous or close to necrosis. Therefore, Doppler examination cannot reliably distinguish between normal and abnormal appendix. (Figure 3C) $[8,18,38,39,40]$

\subsubsection{Computed Tomography (CT)}

CT represents an excellent diagnostic alternative for all other patients. CT is complementary to US and is recommended whenever US results are suboptimal, indeterminate, or normal in patients with acute abdominal pain. US is also complementary to $\mathrm{CT}$ and may be particularly useful in thin patients in whom the results of initial CT, no matter how it is performed, are equivocal. CT to be superior to graded compression US in the diagnosis of acute appendicitis. Analysis of the data for CT and US revealed similar specificities $(89 \%$ vs $91 \%$, respectively) and positive predictive values ( $96 \%$ vs $95 \%$, respectively); however, CT demonstrated higher sensitivity ( $96 \%$ vs $76 \%$ ), accuracy $(94 \%$ vs $83 \%)$, and negative predictive value (95\% vs $76 \%)$. CT was shown to be more accurate in staging periappendiceal inflammation, more useful in diagnosing acute abdominal conditions unrelated to appendicitis, and more sensitive in demonstrating a normal appendix and in excluding acute appendicitis from the differential diagnosis. $[2,6,8,28,38,39,40,41]$

$\mathrm{CT}$ is a highly accurate and effective cross-sectional imaging technique for diagnosing and staging acute appendicitis. CT is readily available, is operator-independent, is relatively easy to perform, and has results that are easy to interpret. Moreover, extremes of body habitus rarely limit study acquisition or interpretation when optimized scanning methods are used. [8]

Helical CT has reported sensitivities of $90 \%$ to $100 \%$, specificities of $91 \%$ to $99 \%$, accuracies of $94 \%$ to $98 \%$, positive predictive values of $92 \%$ to $98 \%$, and negative predictive values of $95 \%$ to $100 \%$ for the diagnosis of acute appendicitis. These results are comparable to those achieved by experienced investigators who have used thin-section, conventional, contrast material-enhanced CT and are superior to recently reported clinical accuracy. The diagnostic accuracy of non-contrast $\mathrm{CT}$ for the diagnosis of acute appendicitis in the adult population is adequate for clinical decision making. [2,6,8,28,38,39,40,41]

Appendiceal CT protocols differ considerably with regard to the anatomic area to be included in the scan and to the use of intravenously, orally, and rectally administered contrast material. The most popular and conservative approach is to perform helical CT scanning of the entire abdomen and pelvis with intravenous and oral contrast material. Proponents of this technique believe that contrast-enhanced CT is essential in the diagnosis and staging of numerous inflammatory, ischemic, and neoplasic processes that may cause acute abdominal pain and may simulate appendicitis.

The best results are achieved when the caecum is opacified by contrast, allowing detection of secondary colonic pathology. To take advantage of oral contrast in this way, one must wait one hour or more after administration of oral contrast to image the patient. This delay is the main disadvantage of this protocol, although it is unclear if it is long enough to adversely effect outcomes.

An alternative involves administration of rectal contrast and scanning only the lower abdomen (below the lower pole of the right kidney) and upper pelvis. The reported sensitivity, specificity, and accuracy of this technique are $98 \%$. The inflamed appendix 
usually does not fill with rectal contrast or gas, but if the point of obstruction is not at the base, a small amount of fluid or contrast can leak into the proximal portion of the appendix. Gas also may be present within the inflammed appendix because of the presence of gasforming micro-organisms. [8,18,38,40]

The fastest CT protocol uses a non-enhanced helical CT of the entire abdomen and pelvis. This examination may be performed in 10 minutes, does not expose the patient to the potential risks associated with iodinated contrast agents, requires no bowel preparation, and represents the most cost-effective imaging alternative to US. This procedure is most effective in patients with large body habitus, as diagnostic accuracy may be compromised in patients with little abdominal and intrapelvic fat. These investigators have shown that non-enhanced $\mathrm{CT}$ is an accurate technique for establishing an alternative diagnosis in patients suspected to have appendicitis. $[8,40,41]$

When seen, the normal appendix appears as a tubular or ringlike peri-caecal structure that is either totally collapsed or partially filled with fluid, contrast material, or air. The normal appendiceal wall measures less than 1-2 mm in thickness. The periappendiceal fat should appear homogeneous, although a thin mesoappendix may be present. The inflamed appendix appears as an enlarged blind-ending tubular structure, frequently associated with inflammatory stranding in the surrounding fat. Identification of the appendix is possible with most of the modern CT protocols. The entire appendix should be examined, from caecal insertion to the tip, and the largest transverse diameter should be reported. Traditionally, the threshold diameter of $6 \mathrm{~mm}$ was used for diagnosis of appendicitis. However, studies of healthy adults revealed that the normal range of appendiceal size in an adult patient is 3 to $10 \mathrm{~mm}$. Thus, using an appendiceal threshold size of $9 \mathrm{~mm}$ is more accurate for diagnosis of appendicitis. (Figure 3D) [8]

A definitive CT diagnosis of acute appendicitis can be made if an abnormal appendix is identified or if a calcified appendicolith is seen in association with peri-caecal inflammation. The appearance of the abnormal appendix varies with the stage and severity of the disease process. In patients with mild, non-perforating appendicitis who undergo scanning shortly after the onset of symptoms, the appendix may appear as a minimally distended, fluidfilled, tubular structure 5 to $6 \mathrm{~mm}$ in diameter surrounded by the homogeneous fat attenuation of the normal mesentery. This appearance is seen in only the most incipient forms of acute appendicitis and, in our experience, occurs in fewer than $5 \%$ of patients who undergo scanning. The signs of perforated appendicitis include phlegmon, abscess, extraluminal gas, extraluminal appendicolith, and focal defect in the enhancement of the appendiceal wall. $[2,8]$

\subsubsection{Magnetic Resonance (MR)}

MR imaging is emerging as an alternative to $\mathrm{CT}$ in pregnant patients and in patients who have an allergy to iodinated contrast material. MR imaging has a limited role in the work-up of suspected appendicitis. Although the use of MR imaging avoids ionizing radiation, it has several disadvantages, including high cost, long duration of studies, and limited availability on an emergent basis. According some authors, the use of MR imaging is limited to pregnant patients in whom ultrasound is inconclusive.

There are no known adverse effects of MR imaging in human pregnancy, but the safety of MR imaging has not been proven unequivocally. Although tissue heating from radiofrequency pulses, acoustic stimulation potentially harm the foetus. It remains there for an indefinite amount of time, excreted by the foetal kidneys and subsequently swallowed by the foetus with amniotic fluid. Although there is no evidence of mutagenic or teratogenic 
effects of gadolinium in humans, mutagenic effects were seen in animal studies. Therefore a conservative approach avoids using gadolinium when possible in the first trimester.[40]

On MR imaging, the appendix is identified as a tubular structure with intraluminal T1 and T2 prolongation. Appendicitis is diagnosed using thresholds of the size used for CT. Inflammatory changes are visualized as T2 hyperintensity in the periappendiceal fat. In pregnant women, the abdomen must be examined carefully for an unusual location of the appendix because pregnant uterus displaces the appendix significantly.

\subsubsection{Scintigraphy}

An inflamed bowel has strong chemotactic properties, and leukocytes actively invade the appendix in acute appendicitis. The migration and accumulation of radioactive leukocytes in the appendix is the basis for this study in patients believed to have acute appendicitis. Indium-111-labelled leukocyte scanning had a sensitivity of $86 \%$ and specificity of $93 \%$ for the diagnosis of acute appendicitis. Although the majority of these scans were performed at 2 hours after injection, occasionally delayed images up to 17 to 24 hours were required.

Technetium-99m-albumin-colloid-labelled leukocyte (TAC-WBC) scanning appears to be superior to indium-111 because it is less expensive, requires shorter preparation time, requires less delay in time to positive scan (within 2 hours), and has a lower radiationabsorbed dose, compared with indium-111. The overall sensitivity of this method is of $89 \%$ and its specificity is of $92 \%$ It is not reliable in diagnosing appendicitis in women, with only a $75 \%$ sensitivity and $43 \%$ positive predictive value in this subgroup. Limitations of radionuclide-labelled leukocyte scanning include cost, delay in diagnosis, exposure to radiation, relatively large percentage of indeterminant scans, and decreased sensitivity and specificity in women. [1]

\section{Differential diagnosis}

The differential diagnosis of appendicitis is that of an acute abdomen. At the extremes of age, the threshold for referral for further assessment should be low because of the high mortality associated with delayed presentation or diagnosis. Traditionally, a high negative

\begin{tabular}{|l|l|}
\hline FREQUENT & RARE \\
\hline Acute gastroenteritis & Epiploic appendagitis \\
\hline Acute mesenteric adenitis & Acute pancreatitis \\
\hline Acute cholecystitis & Colonic and appendiceal diverticulitis \\
\hline Intestinal intussusceptions (children) & Intestinal obstruction \\
\hline Perforated peptic ulcer & Crohn's disease \\
\hline Meckel's diverticulitis & Yersiniosis \\
\hline Rectus sheath haematoma & Henoch-Schönlein purpura \\
\hline Right Spighelian hernia & Diabetic ketoacidosis \\
\hline Urinary tract infection & Right pyelonephritis \\
\hline Right uretheral stone & Right pneumonia \\
\hline Ruptured right Graafian follicle & Ruptured ectopic pregnancy \\
\hline Right salpingitis & Pain on the right 10th and 11th dorsal nerves \\
\hline Endometriosis & Porphyria \\
\hline Ovarian torsion & Other abdominal inflammatory conditions \\
\hline
\end{tabular}

Table 6. Differential diagnosis of acute appendicitis. [6,7] 
appendectomy rate of $10 \%$ to $20 \%$ has been considered acceptable to minimize the number of missed cases of appendicitis. However, removal of a normal appendix is associated with an early complication rate of $7 \%$ to $13 \%$ and a late complication rate of $4 \%$, hence, it is not a benign procedure. The clinical presentation of acute appendicitis is often atypical and may mimic other abdominal conditions, confounding its clinical diagnosis and resulting in a clinical diagnostic accuracy of only $60 \%$ to $80 \%$. (Table 6 ) [6,7]

\section{Complications}

Any delay of time for treating acute appendicitis is unwarranted. When the total time interval of symptoms was less than 12 hours, $94 \%$ of patients had simple appendicitis, but $6 \%$ had perforation. Rupture rates rise significantly 36 hours after presentation symptoms. The overall incidence of perforation is $16 \%$ to $39 \%$. Perforation rates are strongly age related and are highest in the very young ( $40 \%$ to $57 \%)$ and in the elderly (55\% to $70 \%)$, in whom misdiagnosis and delayed diagnosis are common. The relationship between diagnostic accuracy and perforation remains controversial. (Figure 4D) $[3,5,8,11]$

In patients with a delayed presentation, a tender mass with overlying muscle rigidity may be felt in the right iliac fossa. The presence of a mass may be confirmed on ultrasonography or computed tomography scan; underlying neoplasm must be excluded, especially in elderly people. [7]

Patients with an appendix abscess have a tender mass with a swinging pyrexia, tachycardia, and leukocytosis. The abscess is most often located in the lateral aspect of the right iliac fossa but may be pelvic; a rectal examination is useful to identify a pelvic collection. The abscess can be shown by ultrasonography or computed tomography scanning, and a percutaneous radiological drainage may be done. Open drainage has the added advantage of allowing an appendectomy to be done.[5,7]

A history of appendectomy is associated with delayed onset of disease and a less severe disease phenotype in patients with ulcerative colitis. The influence of appendectomy in Crohn's disease is not as clear; some evidence suggests a delayed onset of disease in patients after appendectomy, although contradictory evidence also exists to suggest an increased risk of developing the condition depending on the patient's age, sex, and diagnosis at the time of operation. There are circumstantial reports that suggest association between inflammatory bowel or intestinal cancer and appendicitis. However there is no scientific evidence of such an association. Otherwise, chronic appendicitis does not seem to represent any risk of cancer. [7]

\section{Therapeutic decisions}

Appropriate care followed by expedient appendectomy is the treatment of choice. No evidence exists to support the notion that analgesia should be withheld on the grounds that it may cloud the clinical picture. All patients should receive broad spectrum perioperative antibiotics (one to three doses), as they have been shown to decrease the incidence of postoperative wound infection and intra-abdominal abscess formation. [7,42]

According to some authors, the initial nonoperative management of these patients has been established as safe and effective, and is likely the preferred method of treatment. [29,43]

\subsection{Non-operative treatment}

Non-operative management with antibiotics has been established for the treatment of uncomplicated diverticulitis, salpingitis, enterocolitis and other abdominal inflammatory 
diseases. It is surprising that non-operative management of uncomplicated acute appendicitis remains largely unexplored despite evidence that uncomplicated acute appendicitis often resolves, either spontaneously or with antibiotic therapy, and has been shown by limited studies to have outcomes equivalent to those of appendectomy. $[17,40,42,43,44]$

Evidence suggests that spontaneous resolution of untreated, non-perforated appendicitis is common and that perforation can be prevented. This motivates a shift in focus from the prevention of perforation to the early detection and treatment of advanced appendicitis. In patients with an equivocal diagnosis where advanced appendicitis is deemed less likely a correct diagnosis is more important than a rapid diagnosis. These patients can safely be managed by active observation with an improved diagnostic work-up under observation. $[15,40,43,44]$

Appendicitis can be treated non-operatively with IV antibiotics with the performance of percutaneous drainage if an abscess is present. There are several schemes of antibiotics (usually cefoxitin and gentamicin or trimethoprim/sulfamethoxazole and metronidazole) described in the literature, all of them with good results. (Table 7) [17,42]

Success rates have been reported as between $88 \%$ and $100 \%$, with the incidence of recurrent appendicitis $5 \%$ to $38 \%$. The protocol for suspected acute appendicitis consists of bowel rest and parenteral fluids. Antibiotics active against gram-negative and anaerobic organisms should be administered. Initial successful nonoperative management is achieved in $95 \%$ of patients. The incidence of progression to diffuse peritonitis during nonoperative treatment for palpable periappendiceal mass is $0.6 \%$ to $5 \%$. Progression to peritonitis is a concern, because patients without a palpable mass may not have developed localization and isolation of appendicitis. This condition is more frequent in elders and in immunossupressed patients, such as those in use of steroids, chemotherapy, etc. These patients should not been included in non-operative protocols. [16,29,40,43,44]

Over the initial 48 to 72 hours of hospitalization, the patients must be serially examined. If the patient's abdominal examination deteriorated or if the patient subjectively or objectively did not improve, percutaneous abscess drainage is undertaken if possible. If a fluid collection amenable to drainage did not exist, urgent appendectomy is undertaken. If the patient improved, parenteral antibiotics are continued until the patient remained afebrile for 24 hours. The average length of hospitalization is one week. [29]

\begin{tabular}{|l|l|c|c|}
\hline AUTHOR & ANTIBIOTIC (IV) & SUCCESS & RECURRENCE \\
\hline Coldrey (1959) & $\begin{array}{l}\text { Penicillin + streptomycin } \\
\text { +chloramphenicol }\end{array}$ & 92 & 14 \\
\hline Adams (1990) & Clindamycin + gentamicin & 56 & 13 \\
\hline Eriksson, Granstrom (1995) & Cefotaxime + tinidazole & 95 & 35 \\
\hline Winn et al. (2004) & Gentamicin + metronidazole & 92 & 5 \\
\hline Styrud et al. (2006) & Cefotaxime + tinidazole (IV) & 88 & 14 \\
\hline
\end{tabular}

Table 7. Clinical studies documenting success and recurrence (percentages) of non-operative management (with antibiotics) of uncomplicated acute appendicitis. $[15,16,17,29,40]$

\subsection{Operative treatment}

The treatment of appendicitis depends on both the patient's general condition and the state of the appendix. Traditionally, open appendectomy has been done through a muscle 
splitting gridiron incision over McBurney's point made perpendicular to a line joining the umbilicus and anterior superior iliac spine or through a more cosmetically acceptable Lanz's incision. The proportion of open procedures done has fallen with the increased use of laparoscopic techniques. The use of drains has not proved useful except perhaps in cases of walled-off abscess cavities. [23] When the process is spread as a general peritonitis, a median or a right medial paramedian pararectal incision are indicated, in order to aspirate the septic secretion and to treat all complications. Abdominal drainage did not prove to have any benefit. [45]

Since the advent of laparoscopic surgery for appendectomy in 1983, its use has steadily increased through the past decade. Laparoscopy is now the standard method of investigating acute lower abdominal pain. If appendectomy is considered necessary, then it is logical to remove the appendix using laparoscopic techniques. The proposed advantages of laparoscopic compared with open appendectomy have seemed less compelling than laparoscopy in other abdominal procedures, and many surgeons still favour open repair because they believe that the overall morbidity is primarily a function of the degree of appendicitis. Compared with open surgery, a systematic review found that laparoscopic appendectomy in adults reduces wound infections, postoperative pain, length of hospital stay, and time taken to return to work. In children, laparoscopic appendectomy reduced the number of wound infections and the length of hospital stay compared with open surgery, but no significant differences in postoperative pain, time to mobilisation, or proportion of intra-abdominal abscesses were seen. $[13,45,46,47,48]$

With advances in laparoscopic instruments and skills, laparoscopic single-port surgery has been developed and applied to appendectomy. It offers better cosmetic results (scarless abdominal surgery via umbilical incision), less incisional pain, and the capability to convert to multiport surgery if required. [49,50,51,52,53,54,55]

\subsection{Perioperative period}

Children with appendicitis are often dehydrated and may be febrile, acidotic, and septic. Intravenous fluids and antibiotics are always indicated preoperatively. All the patients followed the same preoperative protocol, with antibiotic prophylaxis before the operation and postoperative antibiotic treatment according to the macroscopic characteristics of the appendix and whether purulent free liquid into the abdominal cavity was present or not.

The antibiotic regimen selected should be effective against the bacterial flora found in the appendix, which consists chiefly of anaerobes and gram-negative coliforms. Anaerobes make up most of the colonic flora and include Bacteroides, Clostridial, and Peptostreptococcus species. Gram-negative aerobes, such as Escherichia coli, Pseudomonas aeruginosa, Enterobacter, and Klebsiella, are also important. Gram-positive organisms are less commonly found in the colon, and the need for coverage for them (primarily Enterococcus) is controversial.

For non-perforated appendicitis, a single agent such as cefoxitin, cefotetan, ampicillin/sulbactam, ticarcillin/clavulanate, or piperacillin/tazobactam is typically prescribed. In cases of perforated appendicitis, most surgeons select either traditional "triple" antibiotics (ampicillin, gentamycin, and clindamycin or metronidozole or piperacillin/tazobactam) or a combination such as ceftriaxone/metronidozole or ticarcillin/clavulante plus gentamycin. [11,14,42]

Appendectomy is a relatively safe procedure with a mortality rate for non-perforated appendicitis of 0.8 per 1000 . The mortality and morbidity are related to the stage of disease 
and increase in cases of perforation; mortality after perforation is 5.1 per 1000 . As stated above, the average rate of perforation at presentation is between $16 \%$ and $30 \%$, but this is significantly increased in elderly people and young children, in whom the rate can be up to $97 \%$, usually because of a delay in diagnosis. Wound complications, ileum, and partial small bowel obstruction are the most common complications. [7,29]

The increased mortality and morbidity associated with perforation has been used as justification for high rates of negative appendectomy, quoted as between $20 \%$ and $25 \%$. Despite this, complications can occur after removal of a normal appendix, and the surgical community continues to strive to reduce the numbers of negative procedures. According to a large historical cohort study, a perforated appendix during childhood does not seem to have a long term detrimental effect on subsequent female fertility.

The rate of postoperative wound infection is determined by the intraoperative wound contamination. Rates of infection vary from $<5 \%$ in simple appendicitis to $20 \%$ in cases with perforation and gangrene. The use of perioperative antibiotics has been shown to decrease the rates of postoperative wound infections. For perforated appendicitis, LA is associated with a higher rate of intra-abdominal abscess drainage and intraoperative complications compared with OA. In contrast, there is a trend towards significance for LA to be associated with lower rates of wound infections and postoperative intestinal obstructions. $[7,42,45,48,50]$

Intra-abdominal or pelvic abscesses may form in the postoperative period after gross contamination of the peritoneal cavity. The patient presents with a swinging pyrexia, and the diagnosis can be confirmed by ultrasonography or computed tomography scanning. Abscesses can be treated radiologically with a pigtail drain, although open or per rectal drainage may be needed for a pelvic abscess. The use of perioperative antibiotics has been shown to decrease the incidence of abscesses. Male and older patients also had an increased risk of intra-abdominal abscess drainage. [7,42,45,48,50]

Wound infections are the most common complication, yet they are substantially less common in children than in adults and may not be related to type or timing of antibiotics or to the type of postoperative wound management. [14,42]

Mortality from appendectomies has been strongly linked to 2 factors in particular-patient age and diagnosis at time of surgery. [2,3]

The most common complications found during the early postoperative period are wound infections and local abscess. After perforated or gangrenous appendicitis subphrenic and pelvic abscesses may occur as well. Peritonitis fistulas and incisional hernias are complications provoked by a not well conducted surgery and may be considered iatrogenic damages that should not occur. All these adverse events are followed by disturbances on the metabolic response to trauma.

\section{Final considerations}

The appendix is still a mysterious organ. Despite the over 150 years of intense research and many thousands researches developed on all fields related to the appendix we still do not know what is the role of this organ. A hypothesis suggests this organ is turning down and going to disappear. However this is still a very controversial theory not accepted by most of investigators. However this is still a very controversial theory not accepted by most of investigators.

The pathophysiology of appendicitis is still not established. The theory that ascribes to an obstructive phenomenon the initial stage of appendicitis was not proved and it is not 
possible to provoke appendicitis in an experimental model. We do not have idea about the role of the enterochromaffin cells in the appendix. Adenocarcinoma is the main cancer of all the digestive system except in the appendix where the characteristic tumour is the carcinoid. Many other doubts have been proposed without satisfactory response.

Traditionally, when the medicine is not able to understand a disease, the removal of the organ is indicated. For this reason most of physicians still prefer appendectomy as the best treatment to heal appendicitis. The advances in technology allowed a safer operations with aesthetically best results, without complications, and no death is accepted independently the stage of the inflammation. On the other side even the clinical treatment based on antibiotics is able to heal this inconvenient disease.

We are not able to preview the future of the studies on appendicitis and its treatment, but for sure all the investigations will make possible to understand this fascinating organ its inflammation and indicate the best treatment and even prevent its occurrence.

\section{Acknowledgment}

The author gratefully thanks Dr. Rogério Augusto Pinto da Silva for the ultrasound images

\section{References}

[1] Graffeo CS, Counselman FL. Appendicitis. Emerg Med Clin N Am 1996; 14: 653-671.

[2] Shelton T, McKinlay R, Schwartz RW. Acute appendicitis. Curr Surg 2003; 60: 502-505.

[3] Hawkins JD, Thirlby RC. The accuracy and role of cross-sectional imaging in the diagnosis of acute appendicitis. Adv Surg 2009; 43: 13-22.

[4] Petroianu A, Oliveira Neto JE, Alberti LR. Incidência comparativa da apendicite aguda em população miscigenada, de acordo com a cor da pele. Arq Gastroenterol 2004; 41: 24-6.

[5] Prystowsky JB, Pugh CM, Nagle AP. Acute appendicitis. Curr Probl Surg 2005; 42: 688692.

[6] Hlibczuk V, Dattaro JA, Jin Z, Falzon L,. Brown MD. Diagnostic accuracy of noncontrast computed tomography for appendicitis in adults. Ann Emerg Med 2010; 55: 51-59.

[7] Humes DJ, Simpson J. Acute appendicitis. Br Med J 2006; 333: 530-534.

[8] Birnbaum BA, Wilson SR. Appendicitis at the millennium. Radiology 2000; 215: 349-352.

[9] Williams GR, A history of appendicitis Ann Surg 1983; 197: 495-506.

[10] Smith DC. Appendicitis, appendectomy, and the surgeon. Bull Hist Med 1996; 70: 414441.

[11] Evans SRT. Appendicitis. Ann Surg. 2006; 244: 661-662.

[12] Malik AA, Wani NA. Continuing diagnostic challenge of acute appendicitis. Aust New Zeal J Surg 1998; 68: 504-505.

[13] Pomp A. Laparoscopy and acute appendicitis. Can J Surg; 1999; 42: 326-327.

[14] Morrow SE, Newman KD. Current management of appendicitis. Sem Pediat Surgery 2007; 16: 34-40.

[15] Andersson RE. The natural history and traditional management of appendicitis revisited. World J Surg 2006; 31:86-92.

[16] Campbell MR, Johnston SL, Marshburn T, Kane J, Lugg D. Nonoperative treatment of suspected appendicitis in remote medical care environments. J Am Coll Surg 2004; 198: 822-830. 
[17] Mason RJ. Surgery for appendicitis. Surg Infect 2008; 9: 481-488.

[18] Rybkin AV, Thoeni RF. Current concepts in imaging of appendicitis. Radiol Clin N Am 2007; 45: 411-422

[19] Bolandparvaz S, Vasei M, Owji AA, Ata N, Amin A, Daneshbod Y, Hosseini SV. Urinary 5-hydroxy indole acetic acid as a test for early diagnosis of acute appendicitis. Clin Biochem 2004; 37: 985-989.

[20] Vasei M, Zakeri Z, Azarpira N, HOSSEINI VS,Dodaran MS. Serotonin content of normal and in inflammed appendix. Acta Pathol Microbiol Immunol Scand 2008; 116: 947-952.

[21] Hernandez R, Jain A, Rosiere L, Henderson SO. A prospective clinical trial evaluating urinary 5-hydroxyindoleacetic acid levels in the diagnosis of acute appendicitis. Am J Emerg Med 2008; 26: 282-286.

[22] Iriarte WLZ, Ito M, Naito S, Nakayama T, Itsuno M, Fujii H, Furukawa M, Makiyama K, Sekine I Cell carcinoid of the appendix. Int Med 1994; 33: 422-426.

[23] Goede, AC; Caplin ME; Winslet MC. Carcinoid tumour of the appendix. Br J Surg 2003; 90: 1317-1322.

[24] Sato VT, Detry O, Polus M, Thiry A, Detroz B, Maweja S, Hamoir E, Defechereux T, Coimbra C, Roover A, Meurisse M, Honoré P. Carcinoid tumour of the appendix. World J Gastroenterol 2006; 12: 6699-6701.

[25] Basaran A; Basaran, M. Diagnosis of acute appendicitis during pregnancy. Obstet Gynecol Survey 2009; 64: 481-488.

[26] Leung NYW, Lau ACW, Chan KKC, Yan WW. Clinical characteristics and outcomes of obstetric patients admitted to the intensive care unit. Hong Kong Med J 2010;16:1825.

[27] Pastore PA, Sauret J. Appendicitis in pregnancy. J Am Board Fam Med 2006;19: 621626.

[28] Neumayer L, Kennedy, A. Imaging in appendicitis. Obstet Gynecol 2003; 102: 14041409.

[29] Oliak D, Yamini D, Udani VM, Lewis RJ, Vargas H, Arnell T, Stamos MJ. Nonoperative management of perforated appendicitis without periappendiceal mass. Am J Surg 2000; 179: 177-181.

[30] Ebell MH. Diagnosis of Appendicitis. Am Fam Physician 2008; 77: 828-830.

[31] Aloo J, Gerstle T, Sgmund II JS. Appendicitis in children less than 3 years of age: a 28year review. Pediatr Surg Int 2004; 19: 777-9.

[32] Sivit CJ. Imaging the child with right lower quadrant pain and suspected appendicitis: current concepts. Pediatr Radiol 2004; 34: 447-53.

[33] Howell JM, Eddy OL, Lukens TW, Thiessen MEW, Weingart SD, Decker WW. Critical issues in the evaluation and management of emergency department patients with suspected appendicitis. Ann Emerg Med 2010; 55: 71-116.

[34] Boleslawski E, Panis Y, Benoist S, Denet C, Mariani P, Valleur P. Plain abdominal radiography as a routine procedure for acute abdominal pain of the right lower quadrant. World J Surg 1999; 23:262-4.

[35] Petroianu A. Faecal loading in the caecum as a new radiological sign of acute appendicitis. Radiography 2005; 11:198-200.

[36] Petroianu A, Alberti LR, Zac RI. Faecal loading in the caecum as a new radiological sign of acute appendicitis. World J Gastroenterol 2005; 11:4230-2. 
[37] Petroianu A, Alberti LR, Zac RI. Assessment of the persistence of faecal loading in the caecum in presence of acute appendicitis. Int J Surg. 2007; 5: 11-6.

[38] Doria AS. Optimizing the role of imaging in appendicitis. Pediatr Radiol 2009; 39 (Suppl 2):S144-S148

[39] Poortman P, Oostvogel HJ, Bosma E et al. Improving diagnosis of acute appendicitis. J Am Coll Surg 2009; 208: 434-41.

[40] Parks NA, Schroeppel TJ. Update on imaging for acute appendicitis. Surg Clin North Am 2011; 91: 141-54.

[41] Krajewski S, Brown J, Phang T, Raval M, Brown CJ. Impact of computed tomography of the abdomen on clinical outcomes in patients with acute right lower quadrant pain. Can J Surg 2011; 54: 43-53.

[42] LeeSL, Islam S, Cassidy LD, Abdullah F, Arca MJ. Antibiotics and appendicitis in the pediatric population. J Pediatr Surg 2010; 45: 2181-5.

[43] Khairy G. Acute appendicitis. Saudi J Gastroenterol 2009; 15: 167-70.

[44] Cobben LPJ, Otterloo AM, Puylaert JBCM. Spontaneously resolving appendicitis. Radiology 2000; 215: 349-352.

[45] Markides G, Subar D, Riyad K. Laparoscopic versus open appendectomy in adults with complicated appenidicitis. World J Surg 2010; 34: 2026-40.

[46] Bhandarkar D, Shah RMC. A novel technique for extraction of the appendix in laparoscopic appendectomy. Surg Laparosc Endosc Percut Tech 2002; 12: 117-118.

[47] Motson RW Kelly MD. Simplified technique for laparoscopic appendectomy. Aust New Zeal J Surg 2002; 72: 294-295.

[48] Liu Z, Zhang P, Ma Y, et al. Laparoscopy or not. Surg Laparosc Endosc Percutan Tech 2010; 20: 362-70.

[49] Wang X, Zhang W, Yang X, Shao J, Zhou X, Yuan J. Complicated appendicitis in children. J Pediat Surg 2009; 44: 1924-1927.

[50] Howard C, Jen MD, Stephen B, Shew MD. Laparoscopic versus open appendectomy in children. J Surg Res 2010; 161: 13-17.

[51] Nakhamiyayev V, Galldin L, Chiarello M, Lumba A, Gorecki PJ. Laparoscopic appendectomy is the preferred approach for appendicitis. Surg Endosc 2010; 24: 859-864.

[52] Lee J, Baek J, Kim W. Laparoscopic transumbilical single-port appendectomy. Surg Laparosc Endosc Percut Tech 2010; 20: 100-103.

[53] Vidal O, Valentini M, Ginestà C, Martí J, Espert JJ, Benarroch G, García-Valdecasas JC. Laparoendoscopic single-site surgery appendectomy. Surg Endosc 2010; 24: 686691.

[54] Akgür FM, Olguner M, Hakgüder G, Ateş O. Appendectomy conducted with single port incisionless-intracorporeal conventional equipment-endoscopic surgery. J Pediat Surg 2010; 45: 1061-1063.

[55] Saber AA, Elgamal MH, Ghazaly TH, Dewoolkar AV, Akl A. Simple technique for single incision transumbilical laparoscopic appendectomy. Int J Surg 2010; 8: 128130. 


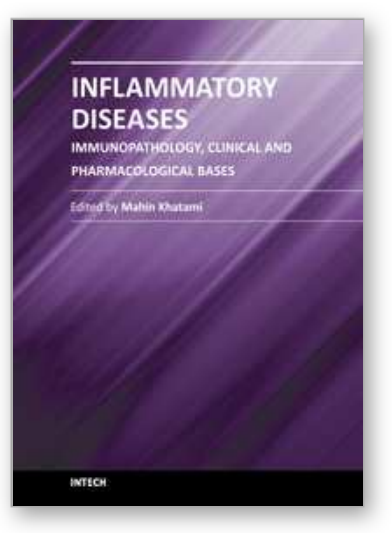

\author{
Inflammatory Diseases - Immunopathology, Clinical and \\ Pharmacological Bases \\ Edited by Dr Mahin Khatami
}

ISBN 978-953-307-911-0

Hard cover, 396 pages

Publisher InTech

Published online 10, February, 2012

Published in print edition February, 2012

This book is a collection of comprehensive reviews contributed by experts in the diverse fields of acute and chronic inflammatory diseases, with emphasis on current pharmacological and diagnostic options. Interested professionals are also encouraged to review the contributions made by experts in a second related book entitled "Inflammation, Chronic Diseases and Cancer"; it deals with immunobiology, clinical reviews, and perspectives of the mechanisms of immune inflammatory responses that are involved in alterations of immune dynamics during the genesis, progression and manifestation of a number of inflammatory diseases and cancers, as well as perspectives for diagnosis, and treatment or prevention of these disabling and potentially preventable diseases, particularly for the growing population of older adults around the globe.

\title{
How to reference
}

In order to correctly reference this scholarly work, feel free to copy and paste the following:

Andy Petroianu (2012). Acute Appendicitis - Propedeutics and Diagnosis, Inflammatory Diseases Immunopathology, Clinical and Pharmacological Bases, Dr Mahin Khatami (Ed.), ISBN: 978-953-307-911-0, InTech, Available from: http://www.intechopen.com/books/inflammatory-diseases-immunopathology-clinicaland-pharmacological-bases/acute-appendicitis-propedeutics-and-diagnosis

\section{INTECH}

open science | open minds

\section{InTech Europe}

University Campus STeP Ri

Slavka Krautzeka 83/A

51000 Rijeka, Croatia

Phone: +385 (51) 770447

Fax: +385 (51) 686166

www.intechopen.com

\section{InTech China}

Unit 405, Office Block, Hotel Equatorial Shanghai

No.65, Yan An Road (West), Shanghai, 200040, China

中国上海市延安西路65号上海国际贵都大饭店办公楼 405 单元

Phone: +86-21-62489820

Fax: +86-21-62489821 
(C) 2012 The Author(s). Licensee IntechOpen. This is an open access article distributed under the terms of the Creative Commons Attribution 3.0 License, which permits unrestricted use, distribution, and reproduction in any medium, provided the original work is properly cited. 